\title{
Combinatorial lentiviral gene delivery of pro-oligodendrogenic factors for improving myelination of regenerating axons after spinal cord injury
}

\author{
Dominique R. Smith ${ }^{1}$ | Daniel J. Margul ${ }^{2}$ | Courtney M. Dumont ${ }^{1}$ | \\ Mitchell A. Carlson ${ }^{1}$ | Mary K. Munsell ${ }^{1}$ | Mitchell Johnson ${ }^{1}$ | \\ Brian J. Cummings $s^{3,4,5,6} \mid$ Aileen J. Anderson ${ }^{3,4,5,6}$ | Lonnie D. Shea ${ }^{1,7}{ }_{0}$
}

${ }^{1}$ Department of Biomedical Engineering, University of Michigan, Ann Arbor, Michigan

${ }^{2}$ Department of Biomedical Engineering, Northwestern University, Evanston, Illinois

${ }^{3}$ Institute for Memory Impairments and Neurological Disorders (iMIND), University of California, Irvine, California

${ }^{4}$ Sue and Bill Gross Stem Cell Research Center, University of California, Irvine, California

${ }^{5}$ Department of Anatomy and Neurobiology, University of California, Irvine, California

${ }^{6}$ Department of Physical Medicine and Rehabilitation, University of California, Irvine, California

${ }^{7}$ Department of Chemical Engineering, University of Michigan, Ann Arbor, Michigan

\section{Correspondence}

Lonnie D. Shea, Department of Biomedical Engineering, University of Michigan, 1119 Carl A. Gerstacker Building, 2200 Bonisteel Blvd, Ann Arbor, MI 48109-2099.

Email: Idshea@umich.edu

Funding information

National Institutes of Health, Grant/Award Number: R01EB005678

\begin{abstract}
Spinal cord injury $(\mathrm{SCl})$ results in paralysis below the injury and strategies are being developed that support axonal regrowth, yet recovery lags, in part, because many axons are not remyelinated. Herein, we investigated strategies to increase myelination of regenerating axons by overexpression of platelet-derived growth factor (PDGF)-AA and noggin either alone or in combination in a mouse $\mathrm{SCl}$ model. Noggin and PDGF-AA have been identified as factors that enhance recruitment and differentiation of endogenous progenitors to promote myelination. Lentivirus encoding for these factors was delivered from a multichannel bridge, which we have previously shown creates a permissive environment and supports robust axonal growth through channels. The combination of noggin+PDGF enhanced total myelination of regenerating axons relative to either factor alone, and importantly, enhanced functional recovery relative to the control condition. The increase in myelination was consistent with an increase in oligodendrocyte-derived myelin, which was also associated with a greater density of cells of an oligodendroglial lineage relative to each factor individually and control conditions. These results suggest enhanced myelination of regenerating axons by noggin+PDGF that act on oligodendrocyte-lineage cells post- $\mathrm{SCl}$, which ultimately led to improved functional outcomes.
\end{abstract}

KEYWORDS

gene therapy, myelination, spinal cord injury (SCI), tissue engineering

\section{1 | INTRODUCTION}

Spinal cord injury $(\mathrm{SCl})$ causes paralysis below the level of injury, which, at the cellular level, results from a neuron and oligodendrocyte cell death, axonal loss, and demyelination (Laporte et al., 2009; Richardson, McGuinness, \& Aguayo, 1980; Tuinstra et al., 2012). Though spinal cord neurons have an innate capacity to regenerate, they are limited by a microenvironment that features an insufficient supply of factors that promote regeneration and an abundance of inhibitory factors including the glial scar (Beattie, Hermann, Rogers, \& Bresnahan, 2002; Bunge, 2001; Donnelly \& Popovich, 2008; Fitch \& Silver, 2008; Kadoya et al., 2009; Schmidt \& Leach, 2003; Schwab, 2002). Postmitotic oligodendrocytes, the myelinating cells native to the central nervous system (CNS), infrequently myelinate regenerating axons as oligodendrocytes undergo apoptosis due to excitotoxicity and the inflammatory milieu 
(Casha, Yu, \& Fehlings, 2001; Li, Farooque, Holtz, \& Olsson, 1999; Lytle \& Wrathall, 2007). Remyelination by Schwann cell of the peripheral nervous system (PNS) is observed, though it is expected that Schwann cell-derived myelin is less effective for CNS function (Zhang, Huang, Gates, \& Holmberg, 2013). Surviving oligodendrocytes are inefficient at the proliferation or extensive migration that is necessary for the cells to myelinate the majority of regenerating axons (Almad, Sahinkaya, \& McTigue, 2011; Lytle \& Wrathall, 2007). Thus, strategies are needed to overcome the inhibitory microenvironment for enhancing the number of available oligodendrocytes, such as through the recruitment of endogenous progenitors, and supporting their capacity for myelination (Almad et al., 2011; Barnabé-Heider et al., 2010; Mi et al., 2009; Sellers, Maris, \& Horner, 2009).

Modulating the microenvironment following injury has proven to be difficult, with a multitude of the cell, gene, and biomaterial approaches having been evaluated. Transplantation of Schwann cells, stem cells, or cells genetically engineered to secrete inductive factors have been used to shift the microenvironment towards a proregenerative phenotype (B. K. Chen et al., 2017; Fortun, Hill, \& Bunge, 2009; Pearse \& Barakat, 2006). However, the impact of cell transplantation is frequently limited by the extent of survival and engraftment (Li \& Lepski, 2013; Tetzlaff et al., 2011), which may not provide factors for the times that are necessary to promote regeneration. Alternatively, injection of proteins into the lesion space or the spinal cord parenchyma has been used to deliver trophic factors, yet these strategies cannot sustain the presence of these factors due to their clearance or degradation. Gene delivery represents a versatile strategy in which transduced cells function as bioreactors for the localized production of trophic factors to create a permissive environment for regeneration. We have previously reported that poly(lactide-co-glycolide) (PLG) multichannel bridges are an effective vehicle for localized, sustained lentiviral gene therapy capable of altering the postinjury microenvironment and promoting regeneration (Tuinstra et al., 2012). PLG has been widely used as a material for spinal cord repair or peripheral nerve conduits. PLG is also biodegradable, bioresorbable, and its degradation products are cleared by the body (Wang et al., 2011). The lentiviral expression is highest at the site of the implant and decreases as a function of distance. The lentivirus transduces cells in the surrounding area including astrocytes, macrophages, fibroblasts, and invading Schwann cells (Tuinstra et al., 2012). In addition, these bridges feature an architecture that encourages axon growth through channels and the infiltration of supporting cells into interconnected pores (Tuinstra et al., 2012, 2014). Regenerating axons have been observed growing through the bridge and into tissue caudal to the injury (Pawar et al., 2015). However, the bridge alone is limited in its ability to foster remyelination. We have previously reported on the combinatorial delivery of sonic hedgehog (SHH) and neurotrophin 3 (NT3) to improve myelination of regenerating axons. SHH and NT3 are reported to promote neurite extension that is dependent on the concentration and spatial/ temporal distribution (Delgado et al., 2014; Marti \& Bovolenta,
2002), with SHH also influencing neuronal and oligodendrocyte differentiation during development and following injury (Gritli-Linde, Lewis, McMahon, \& Linde, 2001; Lowry et al., 2012). While SHH alone, but not its combination with NT3, was able to enhance the percentage of axons myelinated by oligodendrocytes, the overall percentage of myelinated axons was lower than that normally found in the contralateral tissue. This could be attributed to NT3 promoting Schwann cell recruitment and progenitor quiescence (Delgado et al., 2014). SHH has also been associated with ventral patterning but has not been shown to enhance the progenitor recruitment necessary to generate myelinating oligodendrocytes (Ribes \& Briscoe, 2009). Factors that more effectively recruit the endogenous progenitor pool toward an oligodendrocyte lineage may further enhance myelination.

Noggin and platelet-derived growth factor (PDGF)-AA have been identified as factors that enhance recruitment and differentiation of endogenous progenitors to promote myelination in vitro and in vivo. Noggin is a bone morphogenetic protein (BMP) receptor antagonist (Liu \& Niswander, 2005). BMPs, which are upregulated after SCl, promote astrocyte differentiation of proliferating progenitor cells. Although noggin inhibits the BMP pathway, it is not sufficient to increase the overall differentiation of progenitor cells to myelinating oligodendrocytes (Enzmann et al., 2005). PDGF specifically, has been noted for its capacity to enhance proliferation and recruitment of progenitor cells both in vitro and in vivo (Y. Chen et al., 2007; Hill, Patel, Medved, Reiss, \& Nishiyama, 2013; Woodruff, Fruttiger, Richardson, \& Franklin, 2004; Zhang, Vutskits, Calaora, Durbec, \& Kiss, 2004). PDGF is a potent mitogen for progenitor cell proliferation (Asakura, Hunter, \& Rodriguez, 1997; Woodruff et al., 2004) and is a required signaling molecule for differentiation of embryonic and adult neural stem cells into $\mathrm{O}^{+}$oligodendrocytes (Bradl \& Lassmann, 2010; Hinks \& Franklin, 1999; Hu et al., 2008). These reports elucidated how inductive factors can increase progenitor activity after $\mathrm{SCl}$ and even encourage spontaneous remyelination of spared axons (Lasiene, Shupe, Perlmutter, \& Horner, 2008; Powers et al., 2012; Powers et al., 2013); however, the ability of these endogenous progenitors to potentiate myelination of large numbers of newly regenerating axons has not been determined.

In this report, we investigated noggin and PDGF individually or in combination for their ability to enhance myelination of regenerating axons growing through a biomaterial bridge implanted into an acute spinal cord lesion. A mouse lateral hemisection model was used, with immediate intervention with PLG bridges inserted into the injury to deliver lentiviral vectors for sustained and localized expression of noggin and/or PDGF (Margul et al., 2016; Thomas et al., 2014). Immunohistochemistry (IHC) was initially used to quantify the extent of axon growth and myelination, and functional recovery was quantified using the Basso Mouse Scale (BMS) scale. As myelination can occur from CNS-derived oligodendrocytes or PNS-derived Schwann cells, we quantified the source of myelinating cells, as well as the density of cells within the oligodendrocyte lineage. Collectively, these studies demonstrate the potential for synergy between biomaterials for guiding tissue growth and the localized expression of 
factors for modulating the local environment and enhancing the recruitment of endogenous progenitors that can restore function.

\section{2 | MATERIALS AND METHODS}

\section{1 | Virus production and validation}

HEK-293FT cells (80-90\% confluent; American Type Culture Collection, Manassas, VA) were transfected with third generation lentiviral packaging vectors and pLenti-CMV-Luciferase, pLentiCMV-noggin, or pLenti-CMV-PDGF. Correct insertion was validated via DNA sequencing. Plasmids were incubated in Opti-MEM (Life Technologies, Carlsbad, CA) with Lipofectamine 2000 (Life Technologies) for $20 \mathrm{~min}$ before being added to cells. After $48 \mathrm{hr}$ of incubation, the supernatant was collected, centrifuged to remove cellular debris, and then incubated with PEG-It (System Biosciences, Palo Alto, CA) for 16 to $24 \mathrm{hr}$ at $4^{\circ} \mathrm{C}$. The virus was centrifuged at $1,500 \mathrm{~g}$ at $4^{\circ} \mathrm{C}$ for $30 \mathrm{~min}$, the supernatant was removed, and the pellet was resuspended in sterile phosphate buffered saline (Life Technologies). Viral solution was aliquoted and frozen at $-80^{\circ} \mathrm{C}$ until use. Viral titers used throughout the study were $3 \mathrm{E} 9 \mathrm{IU} / \mathrm{ml}$ as determined by the Lentivirus qPCR Titer Kit (Applied Biological Materials, Richmond, BC, Canada).

\section{2 | Fabrication of multichannel bridges}

Bridges were fabricated using a sacrificial template variation ( $\mathrm{Li}$, Rickett, \& Shi, 2009) of the gas foaming/particulate leaching technique, as previously described (Thomas et al., 2013; Tuinstra et al., 2012). Briefly, PLG (75:25 lactide:glycolide; i.v. $0.76 \mathrm{dl} / \mathrm{g}$; Lakeshore Biomaterials, Birmingham, $\mathrm{AL}$ ) was dissolved in dichloromethane $(6 \% \mathrm{w} / \mathrm{w})$ and emulsified in $1 \%$ poly(ethylene-alt-maleic anhydride) using a homogenizer (PolyTron 3100; Kinematica AG, Littau, Switzerland) to create microspheres (z-average diameter approximately $1 \mu \mathrm{m}$ ). D-Sucrose (Sigma-Aldrich), D-glucose (SigmaAldrich), and dextran MW 100,000 (Sigma-Aldrich) were mixed at a ratio of 5.3:2.5:1 respectively by mass. The mixture was caramelized, cooled, and drawn from the solution with a Pasteur pipette to make sugar fibers. Fibers were drawn to 150 to $250 \mu \mathrm{m}$, coated with a 1:1 mixture of PLG microspheres and salt $(63-106 \mu \mathrm{m})$ and pressed into a salt-lined aluminum mold. The sugar strands were used to create seven channels and the salt creates a porous structure. The materials were then equilibrated with $\mathrm{CO}_{2}$ gas (800 psi) for $16 \mathrm{hr}$ and then gas foamed in a custom-made pressure vessel. Bridges were subsequently cut into $2.25 \mathrm{~mm}$ sections and leached for $2 \mathrm{hr}$ to remove porogen. The bridges were dried overnight and stored in a desiccator.

\section{3 | Virus loading into bridges}

Viruses were adsorbed onto bridges, with multiple steps to increase lentiviral loading. Before virus addition, the bridges were disinfected in $70 \%$ ethanol and washed with sterile water. The bridges were then dried by touching sterile filter paper to the bridge. Bridges were then saturated with $2 \mu \mathrm{L}$ of the virus. After 2 min of incubation, the sterile filter paper was touched to the surface of the bridge to remove excess moisture. This process was then repeated until a total of $8 \mu$ of virus was added. After the final addition, the bridges were not dried with filter paper and were stored on ice until use. Bridges were used within $3 \mathrm{hr}$ of coating with lentivirus. Lentivirus loading conditions included FLuc, PDGF, noggin, and noggin+PDGF. Lentiviral loading was done to ensure the same number of lentiviral particles per bridge.

\section{4 | Mouse spinal cord hemisection}

All animal procedures were approved and in accordance with the Institutional Animal Care and Use Committee at the University of Michigan. A hemisection model of $\mathrm{SCl}$ was performed as previously described (Thomas et al., 2013) on female C57BL/6 mice (6-8 weeks old; Jackson Laboratories). After administration of bupivacaine (AuroMedics Pharma, Dayton, NJ) $(0.8 \mathrm{ml} / \mathrm{kg})$, a laminectomy was performed at T9-T10 to allow for a $2.25 \mathrm{~mm}$ lateral hemisection for immediate bridge implantation. The injury site was covered using GELFOAM (Pfizer, New York, NY) followed by suturing together of the muscle and stapling of skin. Postoperative care consisted of administration of Enrofloxacin (Norbrook Laboratories Limited, Northern Ireland) $(2.5 \mathrm{mg} / \mathrm{kg}$; daily for 2 weeks), buprenorphine (Par Pharmaceutical, Chestnut Ridge, NY) $(0.1 \mathrm{mg} / \mathrm{kg}$; twice daily for 3 days), and Lactated Ringer's solution (MWI, Boise, ID) $(5 \mathrm{ml} / 100 \mathrm{~g}$; daily for 5 days). Bladders were expressed twice daily until function recovered.

\subsection{IHC and quantitative analysis of nerve regeneration, myelination, and neural progenitor cell differentiation}

Spinal cords were extracted 8 weeks after $\mathrm{SCl}$ and flash frozen in isopentane. For immunofluorescence, spinal cord segments were embedded in Tissue-Tek O.C.T. Compound (Sakura Finetek, Torrance, CA) with $30 \%$ sucrose. Cords were cryosectioned transversely in $18-\mu \mathrm{m}$-thick sections. Antibodies against the following antigens were used for immunofluorescence: neurofilament 200 (NF-200, SigmaAldrich), myelin basic protein (MBP; Santa Cruz Biotech, Dallas, TX), Protein-zero myelin protein (PO; Aves Labs, Tigard, OR), Sox2 (Abcam), Olig2 (Millipore), NG2 (Millipore), and O4 (Millipore). Tissues were imaged on an Axio Observer Z1 (Zeiss, Oberkochen, Germany) using a 10x/0.45 M27 apochromatic objective and an ORCA-Flash 4.0 V2 Digital CMOS camera (C11440-22CU; Hamamatsu Photonics, Hamamatsu, Shizuoka, Japan) or a Nikon A1+ (Nikon Inc., Garden City, NY) using a 60x/1.4 apochromatic objective.

To assess the numbers of regenerated and myelinated axons within the PLG bridge area, NF-200 was used to identify axons, $\mathrm{NF}-200^{+} / \mathrm{MBP}^{+}$to determine the number of myelinated axons, and $\mathrm{NF}-200^{+} / \mathrm{MBP}^{+} / \mathrm{PO}^{+}$to determine the amount of myelin-derived from infiltrating Schwann cells (Thomas et al., 2014). Twenty-one tissues distributed between conditions were counted by two blinded counters to calibrate software for automated counting developed by McCreedy et al. (2016). In short, images were imported into 
MATLAB and the area of the section corresponding to the PLG bridge was outlined. A Hessian matrix was created by convolution filtering using the second derivative of the Gaussian function in the $x$, $y$, and $x y$ directions. Eigenvalues were determined by extraction from the Hessian matrix and used to reconstruct the original image. Following filtering, positive NF-200 events were identified by intensity threshold, single pixel events were removed, and the number of connected objects was identified. This ensures highly branching axons are counted as one object and long axons are also counted as one object. For calibration, the software will output a matrix of potential axon counts based on this method. These values are directly compared with manual counts for the initial 22 tissues used for calibrating the software. The appropriate filter size and threshold sensitivity are selected based on the correlation between the manual and automated counts to appropriately calibrate the software for use in quantifying the remaining tissues that had not been manually counted. To obtain axon densities, total NF-200 counts were divided by the area of the PLG bridge. MBP and PO events were identified similarly. NF-200 objects containing pixel locations overlapping with positive MBP or PO staining were counted and compared to total NF-200 counts. To ensure the appropriate calibration, Pearson's coefficients were compared between counters and between the software and the counter averages.

Nine tissues were selected randomly from the rostral, middle, and a caudal section of the bridge implant from each animal $(n=6)$ of each condition to be counted for progenitors and differentiated cells. Immunopositive cells within the PLG bridges were counted manually by four researchers independently. Due to the PLG material generally exhibiting high background, cells were counted as Olig2 or Sox 2 positive only when the appearance of these markers spatially overlapped Hoechst 33342 counterstaining. Co-staining for multiple markers was always assessed by evaluating overlap of pixels above a set threshold in images acquired over identical sample areas. Colocalization of Sox2 and Olig2 was evaluated to determine the numbers of neural progenitor cells (NPCs) and oligodendrocyte progenitor cells (OPCs). To quantify densities, total immunopositive cells were divided by the area of PLG outlined.

\section{6 | Behavioral analysis}

The BMS open-field locomotor test was used to evaluate functional recovery over a period of 8 weeks after $\mathrm{SCl}$ as previously described (Basso et al., 2006) for FLuc $(n=12)$ and noggin+PDGF $(n=12)$ conditions. A baseline was determined before $\mathrm{SCl}$, and the mice were tested at 1, 2, 4, 6, and 8 weeks. Observations and BMS scoring were performed by two blinded observers for $4 \mathrm{~min}$ per animal.

\section{7 | Statistical analysis}

For multiple comparisons, statistical significance between groups was determined by one-way or two-way analysis of variance with Bonferroni's post hoc. For single comparisons, the statistical significance between pairs was determined by unpaired $t$ test. All statistics test of significance were done using an $\alpha$ value of 0.05 . Error bars represent the standard error in all figures. Prism 7 (GraphPad Software, La Jolla, CA) software was used for all data analysis.

\section{8 | Data availability}

The datasets generated during and/or analyzed during the current study are available from the corresponding author on reasonable request.

\section{3 | RESULTS}

\section{1 | Lentiviral construct validation}

Initial studies validated the lentiviral constructs encoding noggin and PDGF. HEK-293FT cells were transduced with a multiplicity of infection (MOI) of 10 viral particles per cell with noggin-encoding lentivirus. After 3 days, expression of noggin was assessed with an antinoggin antibody with Hoechst 33342 counterstaining (Figure 1a-c). There was substantial staining with anti-noggin antibodies throughout cells transduced with the lentivirus. There is also substantial staining of noggin in the cytosol. PDGF overexpression was validated by transducing HEK-293FT cells with MOI 10 of PDGF lentivirus and quantifying the protein level with an enzyme-linked immunosorbent assay kit. PDGF protein expression increased fourfold over cells transduced with FLuc lentivirus.

\section{2 | Increased axon numbers and myelination after injury}

We quantified axonal density as a function of FLuc, noggin, PDGF, or codelivery of both factors from the bridge. Axons (NF-200 ${ }^{+}$) were present throughout the bridges (Figure 2a-d) 8 weeks after $\mathrm{SCl}$ under all experimental conditions. NF- $200^{+}$axons were typically observed in small groups or bundles as previously reported for multichannel PLG bridges (McCreedy et al., 2016; Tuinstra et al., 2012). FLuc bridges had a mean of approximately 800 axons $/ \mathrm{mm}^{2}$, single lentiviral conditions had approximately 1,100 axons $/ \mathrm{mm}^{2}$, and noggin+PDGF had approximately 1,200 axons $/ \mathrm{mm}^{2}$ (Figure 2e). However, these differences were not statistically significant.

Myelinated axons (NF-200 $/ \mathrm{MBP}^{+}$; Figure $3 \mathrm{a}-\mathrm{d}$ ) were present throughout bridge implants and typically appeared in bundles of multiple axons as previously reported. Myelinated axon density in the bridge implants was significantly enhanced, approximately threefold by codelivery of noggin+PDGF relative to FLuc controls (Figure 3e). While single lentiviral vector delivery increased the density of myelinated axons compared with the FLuc control, it was not significant. The percentage of axons myelinated, which was determined from the ratio of $\mathrm{NF}-200^{+} / \mathrm{MBP}^{+}$axons divided by the total number of $\mathrm{NF}-200^{+}$axons, was approximately $30 \%$ with no differences between groups for the control and individual factor expression (Figure 3f); however, combined noggin+PDGF delivery 

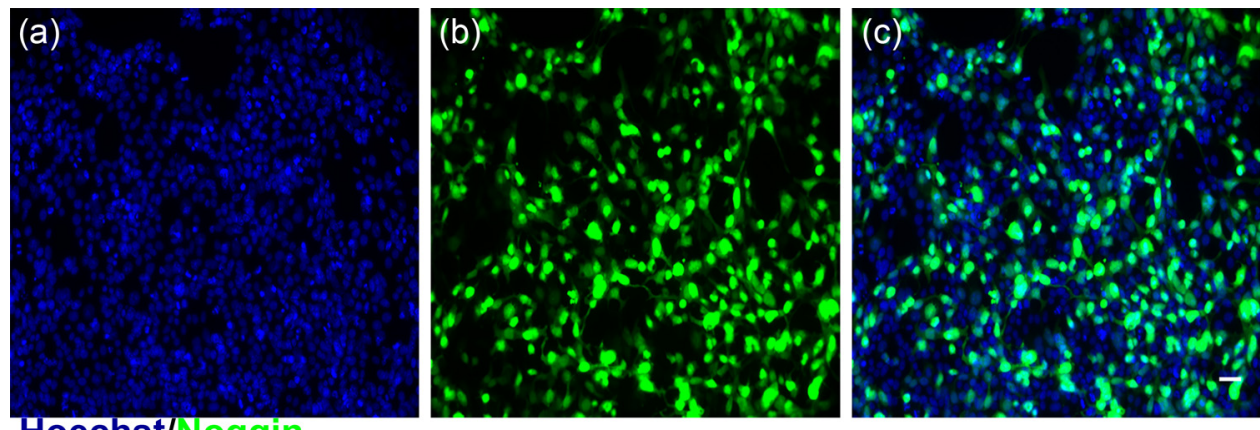

Hoechst/Noggin

(d)

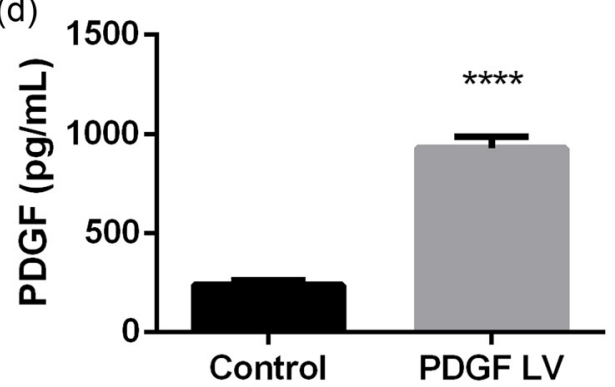

FIGURE 1 Noggin and PDGF expression. (a) Hoechst (blue), (b) Noggin (green), and (c) overlaid images of lentiviral expression of the noggin. (d) Quantification of PDGF secretion protein from cells transfected with no virus (Control) or PDGF lentivirus using ELISA. Data presented as mean \pm S.E.M. Scale: $50 \mu \mathrm{m}^{* * * *} p<0.0001$ versus control. ELISA: enzyme-linked immunosorbent assay; PDGF: platelet-derived growth factor; S.E.M.: standard error of the mean [Color figure can be viewed at wileyonlinelibrary.com]

resulted in a significantly higher percentage of myelinated axons at $44 \%$.

\subsection{Enhanced motor function recovery with combinatorial delivery}

We subsequently investigated the capacity for the combination of PDGF+noggin, which enhanced myelinated, to improve functional recovery. Bridges loaded with noggin+PDGF were implanted into the lateral hemisection, with a control cohort receiving FLuc, and motor function was evaluated for 8 weeks post-SCI using the BMS (Figure 4). Before surgery, all mice were fully functional with perfect scores (BMS =9). At 1-week post-SCI, all mice had no movement in the ipsilateral hindlimb. From week 4 onward, mice receiving noggin+PDGF codelivery had significantly improved function in comparison to mice that received bridges with FLuc lentivirus. Mice receiving noggin+PDGF lentivirus earned an average BMS score of approximately 4.2, with a score of 4 indicating occasional stepping. By comparison, mice from the control condition mice scored at an average of approximately 1.5 , which indicates ankle movement, yet an inability to achieve paw placement or perform stepping.

\subsection{Source of myelination after injury}

The source of myelination in the bridge was subsequently characterized to further investigate the correlation between increased myelination and motor function recovery. Histological sections were immunostained to identify Schwann cell (NF-200 ${ }^{+} / \mathrm{MBP}^{+} / \mathrm{PO}^{+}$) or oligodendrocyte-derived myelin (NF-200 $/ \mathrm{MBP}^{+} / \mathrm{PO}^{-}$; Figure $5 \mathrm{a}-\mathrm{d}$ ).
No significant difference in density of Schwann cell myelinated axons between conditions was observed. In control, noggin, and PDGF conditions, the density of oligodendrocyte-derived myelin was approximately 100 neurites $/ \mathrm{mm}^{2}$. Overexpression of noggin+PDGF resulted in approximately 250 neurites $/ \mathrm{mm}^{2}$, a significant 2.5 -fold increase (Figure 5e). The percentage of oligodendrocyte-derived myelin was determined as the ratio of the number of $\mathrm{NF}-200^{+} / \mathrm{MBP}^{+} /$ $\mathrm{PO}^{-}$axons divided by the total number of $\mathrm{NF}-200^{+}$axons. Overexpression of noggin or PDGF alone resulted in similar percentages of oligodendrocyte-derived myelin as control animals at 11 to $13 \%$. Combined overexpression of noggin+PDGF significantly increased the level of total axons myelinated by oligodendrocytes to $22 \%$ relative to all experimental conditions (Figure 5f).

\subsection{Recruitment and differentiation of endogenous progenitors}

The increase in CNS-derived oligodendrocyte myelination of regenerating axons at 8 weeks after injury within the bridge was subsequently interrogated by quantifying the density of cells within the oligodendroglial lineage. The presence of oligodendrocytes was evaluated by staining for $\mathrm{O} 4$ (Figure $6 \mathrm{a}-\mathrm{d}$ ). Few $\mathrm{O}^{+}$preoligodendrocytes were observed in controls (Figure 6j). A significant increase in $\mathrm{O}^{+}$cells for noggin+PDGF overexpression was observed compared to that in all other experimental conditions (Figure 6j).

Cells in the oligodendrocyte lineage $\left(\mathrm{O}^{+}\right)$can arise from either NPCs that are $\mathrm{Sox}^{2+}$, or from glial-restricted progenitors (Olig2 ${ }^{+} / \mathrm{Sox}{ }^{-}$or $\mathrm{NG}^{2}$ $\left.{ }^{+}\right)$, which were subsequently analyzed. This analysis was performed at the 8-week time point, which would provide enough time for the progenitors 

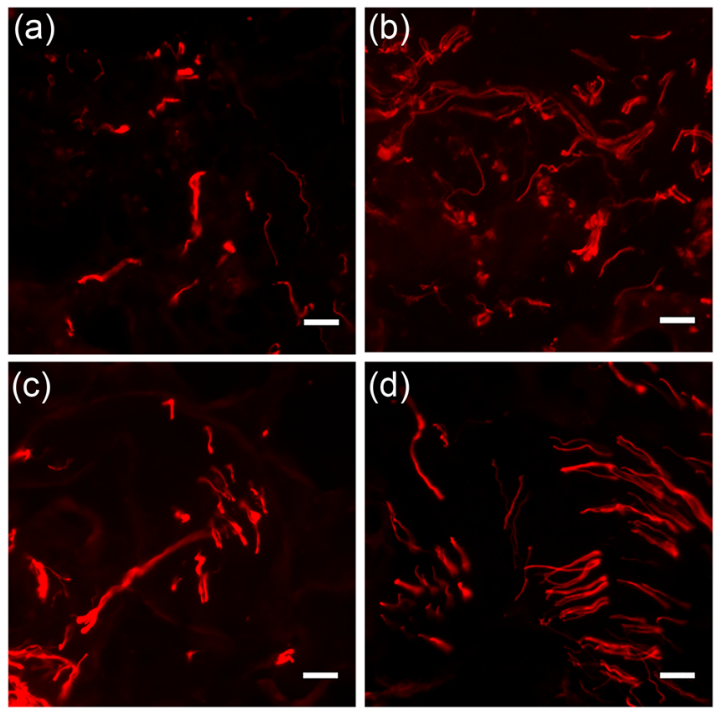

(e)

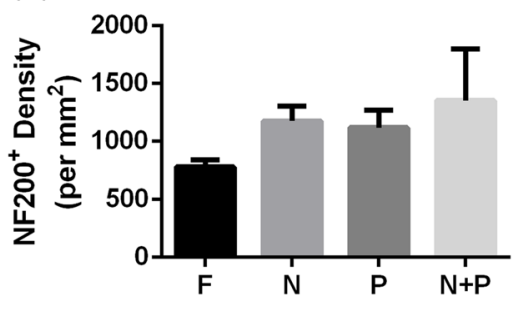

FIGURE 2 Axonal Growth at 8 weeks after injury. NF-200 (red) immunofluorescence from bridge implants delivering (a) FLuc, (b) Noggin, (c) PDGF, or (d) Noggin+PDGF. Brightness and contrast were adjusted for clarity. (e) Quantification of axon density in FLuc, Noggin, PDGF, and Noggin+PDGF conditions. Data presented as mean \pm S.E.M. Scale: $20 \mu \mathrm{m}$. N = 6 per condition. PDGF: platelet-derived growth factor; S.E.M.: standard error of the mean [Color figure can be viewed at wileyonlinelibrary.com]

to develop along multiple lineages. For glial-restricted OPCs (Figure 6b), no significant differences in the density of Olig2 ${ }^{+} / \mathrm{Sox}^{-}$cells or $\mathrm{NG}^{+}$ cells across experimental conditions were observed (Figure 6I). However, the density trended toward an increase in $\mathrm{NG}^{+}$stained cells for all conditions compared with that of the control (Figure 6k). Similar levels of $\mathrm{NG}^{+}$cells levels were present for noggin, PDGF, and the combination of noggin+PDGF overexpression.

For NPCs $\left(\right.$ Sox $\left.2^{+}\right)$, noggin overexpression resulted in no significant difference in a number of Sox $2^{+}$cells relative to FLuc delivery (Figure 61). In contrast, PDGF overexpression trended towards elevated numbers of Sox $2^{+}$cells relative to noggin overexpression. Interestingly, the combination of noggin+PDGF had an additive effect, producing significantly more Sox $2^{+}$cells relative to noggin overexpression alone. We subsequently assessed the colocalization of Sox 2 and Olig2 markers, which represents Sox ${ }^{+}$NPCs in the process of differentiating along oligodendrocyte lineages that lead to the nuclear expression of Olig2 (Barnabé-Heider et al., 2010; Lee, Wu, Chung, \& Wrathall, 2013; Sabelström, Stenudd \& Frisén, 2014). A significant increase in the density of Sox $2^{+} / \mathrm{Olig}^{+}$cells was observed with PDGF overexpression compared with noggin and noggin+PDGF overexpression (Figure 6l), indicating a greater number of NPCs differentiating into OPCs. Collectively, these studies suggest that the combination of PDGF+noggin enhances the recruitment of both glial-restricted progenitors and NPCs toward an oligodendrocyte lineage.

\section{4 | DISCUSSION}

We investigated remyelination of regenerating axons by endogenous cells responding to lentiviral induced trophic factor production by cells recruited into PLG multichannel bridges implanted into a T9-10 mouse lateral hemisection $\mathrm{SCl}$. We have previously reported axonal growth post-SCI through an aligned linear multichannel bridge, which also provides a porous structure for cellular infiltration (Tuinstra et al., 2012, 2014; Yang et al., 2009). These bridges are a valuable tool to study the spinal cord microenvironment after injury and investigate treatments in a controlled and defined manner. The bridges are acellular, indicating that any cells, extracellular matrix, or proteins present in the bridge at the time of extraction must have originated from the host tissue. Similarly, any axons entering the implant must be attributed to either regeneration of injured axons or sprouting of new axons from spared or contralateral tissue. This bridge provides a defined space for histological analysis, analysis of cell populations at and near the lesion site, and treatment outcomes. The bridge alone has supported robust axon ingrowth, myelination, and recovery of some motor function (Pawar et al., 2015). These bridges also provide a vehicle for lentiviral delivery resulting in longterm, localized transgene expression with the delivery of multiple factors which is difficult to achieve and generally requires the use of osmotic pumps (Thomas et al., 2014; Tuinstra et al., 2012). Osmotic pumps can clog, require surgery for removal, and can cause further tissue damage. Other reports have used direct injection of vectors, which may not localize delivery to the injury. Unlike other viral vectors, lentivirus does not influence the phenotype of progenitors (Hughes, Moussavi-Harami, Sauter, \& Davidson, 2002) or cause significant inflammation (Abdellatif et al., 2006). The physical properties of lentiviral vectors are independent of the encoding gene, which allows for the exchange of vectors or the potential to deliver multiple vectors encoding various inductive factors without modification to the base biomaterial creating a high-throughput system. In these studies, we delivered two distinct transgenes from 

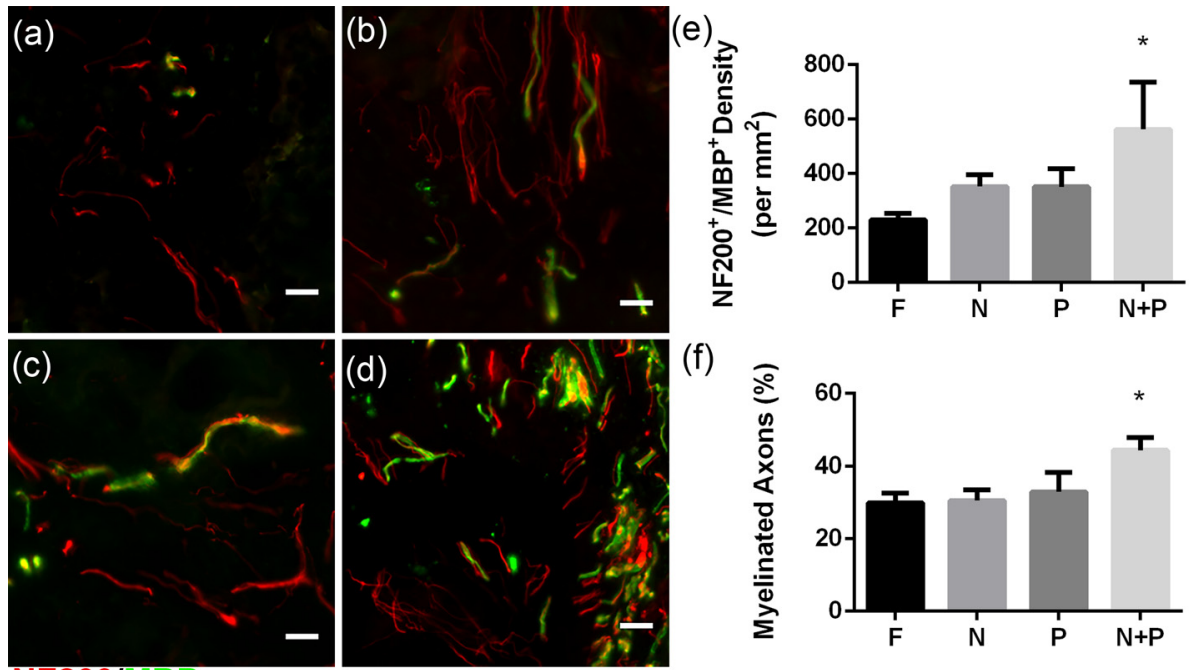

FIGURE 3 Myelinated axons 8 weeks after injury. NF-200 (red) /MBP ${ }^{+}$(green) immunofluorescence from bridge implants delivering (a) FLuc, (b) Noggin, (c) PDGF, or (d) Noggin+PDGF. Brightness and contrast were adjusted for clarity. Quantification of (e) myelinated axon density and (f) percentage of myelinated axons in FLuc, Noggin, PDGF, and Noggin+PDGF conditions. Data presented as mean \pm S.E.M. Scale: $20 \mu \mathrm{m}$. ${ }^{*} p<0.05$ versus FLuc. $N=6$ per condition. MBP: myelin basic protein; PDGF: platelet-derived growth factor; S.E.M.: standard error of the mean [Color figure can be viewed at wileyonlinelibrary.com]

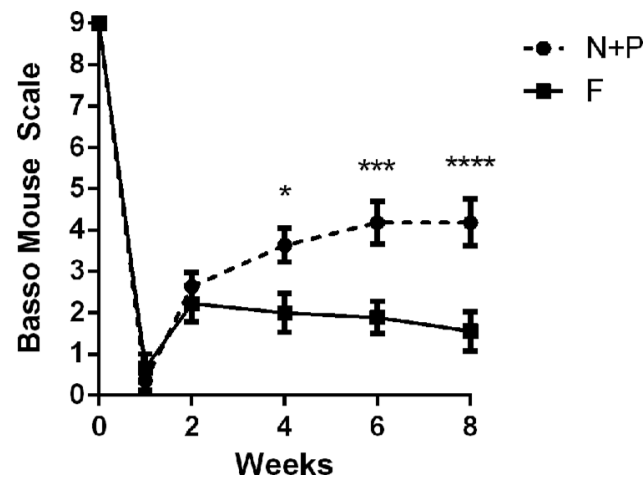

FIGURE 4 Functional recovery induced by Noggin+PDGF codelivery. The Basso Mouse Scale was used to determine differences in motor recovery in the ipsilateral hindlimb. Data presented as mean \pm S.E.M. ${ }^{* *} p<.05$ versus FLuc, ${ }^{* * *} p<.001$ versus FLuc, ${ }^{* * *} p<0.0001$ v. FLuc. $N=12$ per condition. PDGF: plateletderived growth factor; S.E.M.: standard error of the mean

PLG bridges alone and in combination. We have previously demonstrated sustained expression for a minimum of 12 weeks, with peak expression localized within the bridge and decreased expression both rostral and caudal to the bridge (Thomas \& Shea, 2013). This expression pattern ensures the delivered factors can have prolonged, targeted effects on cells within the intact tissue and infiltrating cells within the bridge.

Codelivery of noggin+PDGF significantly increased the density of myelinated axons and achieved the largest percentage of myelinated axons (44\%) and oligodendrocyte-derived myelin (22\%) that we have observed. While codelivery of noggin+PDGF did not significantly increase axon density versus control, the combination did enhance myelination relative to individual factors or control. For comparison of the extent of myelination, delivery of SHH and NT3 in our previous studies only resulted in approximately $30 \%$ of myelinated axons and approximately $13 \%$ of oligodendrocyte-derived myelin when compared with total axon counts (Thomas et al., 2014). Current estimates of myelinated axons in the healthy spinal cord of rodent models range from 40 to $60 \%$ (Chung \& Coggeshall, 1983a, 1983b; Hsu, Stein, \& Xu, 2006). Therefore, this represents a significant result in the enhancement of axon myelination. Reports from other systems have demonstrated varying degrees of remyelination via delivery of single factors (Alizadeh et al., 2017; Tan et al., 2017) or cell transplantation (Cao et al., 2010; B. K. Chen et al., 2017; Deng et al., 2013; Karimi-Abdolrezaee, Eftekharpour, Wang, Morshead, \& Fehlings, 2006), with these reports not achieving the myelination levels reported herein. Lack of myelination has been demonstrated to be a significant hindrance to recovery of function to regenerating axons (Duncan, Brower, Kondo, Curlee, \& Schultz, 2009; Duncan, Marik, Broman, \& Heidari, 2017), and we used the BMS and identified a significant increase in motor function improvement after $\mathrm{SCl}$ compared with that of control. This result suggests the difference in myelination density and percentage may contribute in part to the improved functional outcomes. This result is consistent with other research suggesting remyelination contributes to normal function recovery (Duncan et al., 2009). Another interesting outcome is that no difference in Schwann cell myelin between groups was observed, yet only the noggin/PDGF combination resulted in the improved functional outcome, potentially due to the differences in oligodendrocyte-derived myelination. Oligodendrocyte-derived myelin has been reported to be thicker and more supportive of axonal growth. This suggests that oligodendrocyte-derived myelin is necessary for the return of function and Schwann cell myelin is inefficient.

The increased myelination and functional recovery were associated with a greater recruitment of progenitor cells into the 

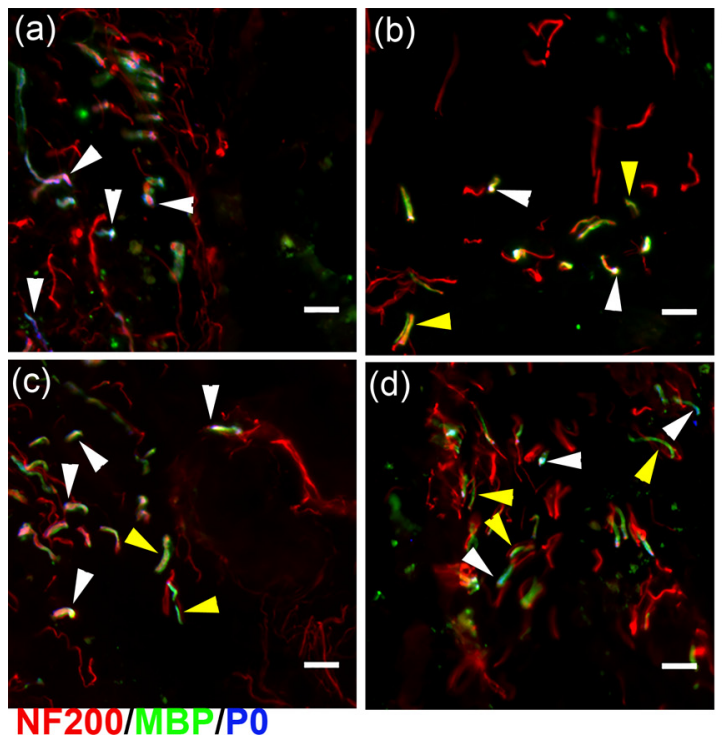

(e)

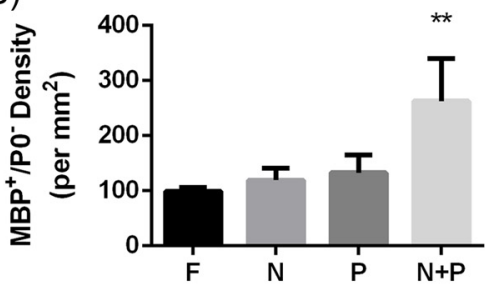

(f)

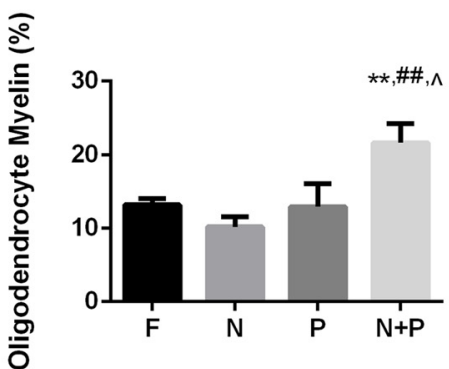

FIGURE 5 Source of myelination 8 weeks after injury. Immunofluorescence from bridges of Schwann cell $\left(\mathrm{NF}^{2}-200^{+} / \mathrm{MBP}^{+} / \mathrm{PO}^{+}: \mathrm{red} / \mathrm{green}\right.$ blue, respectively) and oligodendrocyte (NF-200 $/ \mathrm{MBP}^{+} / \mathrm{PO}^{-}$) derived myelin fibers from bridge implants delivering lentivirus encoding (a) FLuc, (b) Noggin, (c) PDGF, or (d) Noggin+PDGF. White arrows show fibers wrapped by Schwann cell myelin. Yellow arrows show fibers wrapped by Oligodendrocyte myelin. Brightness and contrast were adjusted for clarity. Quantification of (e) oligodendrocyte myelin density and (f) percentage of oligodendrocyte-derived myelinated axons in FLuc, Noggin, PDGF, and Noggin+PDGF conditions. Data presented as mean \pm S.E.M. Scale: $20 \mu \mathrm{m} .{ }^{* *} p<0.01$ versus FLuc, ${ }^{\# \#} p<0.01$ v. Noggin, ${ }^{\wedge} p<0.05$ versus PDGF. $N=6$ per condition. MBP: myelin basic protein; PDGF: platelet-derived growth factor; S.E.M.: standard error of the mean [Color figure can be viewed at wileyonlinelibrary.com]

oligodendrocyte lineage. After the injury, oligodendrocyte-lineage cells have been reported to migrate from the spared tissue to repopulate lost cell populations (Hawryluk \& Fehlings, 2008). These progenitor cells proliferate extensively between $24 \mathrm{hr}$ and 2 weeks after injury but these populations are reduced at later time points (Horky, Galimi, Gage \& Horner, 2006; Sellers et al., 2009). Therefore, many progenitor cell populations would not be expected to be present in the bridges at 8 weeks after injury without trophic factor expression. Our results with the control bridge (i.e., FLuc expression) are consistent with the relatively low density of progenitor cell populations. However, the delivery of lentivirus encoding for noggin, PDGF, or noggin/PDGF combination for sustained transgene expression altered the recruitment and differentiation of progenitor cells. At 8 weeks after injury, endogenous progenitor pools were present within the bridge with trophic factor delivery. NPCs (Sox $2^{+}$) can differentiate into OPCs (Olig2 ${ }^{+}, \mathrm{NG}^{+}$) by exposure to various factors, and OPCs can differentiate into multiple other cell types including oligodendrocytes, astrocytes, Schwann cells, and neurons (Miron, Kuhlmann, \& Antel, 2011). At the $\mathrm{O}^{+}$stage, the cells are lineage locked into becoming mature, myelinating oligodendrocytes. Noggin expression at the bridge would be expected to block the receptors for BMP 2/4/7, which would normally act to inhibit NPC differentiation and migration (Liu \& Niswander, 2005; Sabo, Aumann, Merlo, Kilpatrick, \& Cate, 2011; Xiao, Du, Wu, \& Yip, 2010). The decreased presence of NPCs relative to control with noggin expression is consistent with inhibiting the action of BMPs, which would allow differentiation of NPCs toward an oligodendrocyte lineage. Although noggin alone increased the presence of $\mathrm{O}^{+}$ oligodendrocytes, noggin alone was insufficient to induce myelination of large numbers of regenerating axons.

Delivery of PDGF-encoding lentiviral vectors from the bridge significantly increased the presence of OPCs (Sox $\left.2^{+} / \mathrm{Olig}^{+}\right)$. PDGF in the spinal cord elicits multiple effects on OPCs, such as increasing the proliferation (Y. Chen et al., 2007; Hill et al., 2013; Woodruff et al., 2004) and differentiation (Bradl \& Lassmann, 2010; Hu et al., 2008; Lutton et al., 2012) of OPCs at lesions. In contrast, in vitro, culture studies with oligodendrocytes indicated an inhibition of myelinating properties (Wang, Colognato, \& Ffrench-Constant, 2007), and has been reported to delay oligodendrocyte differentiation and axonal myelination in vivo during development (Butt, Hornby, Kirvell, \& Berry, 1997). However, the distinct effects of PDGF may depend on its temporal availability during proliferation, differentiation, and myelination (Barateiro \& Fernandes, 2014), as withdrawal of this growth factor triggers cell-cycle exit and differentiation (Boulanger \& Messier, 2014). Herein, lentivirus was used for the sustained expression of PDGF for the 8-week study resulting in increased OPC density. However, these increases in OPC density did not contribute to increased density of $\mathrm{O}^{+}$preoligodendrocytes, which is consistent with the lack of increased myelination and oligodendrocyte-derived myelin relative to that of control. Conditional expression systems such as the tetracycline system have been used for temporal control of lentiviral expression (Zhou, Vink, Klaver, Berkhout, \& Das, 2006). This type of viral delivery system could allow for PDGF to be expressed transiently to encourage further maturation of OPCs. 

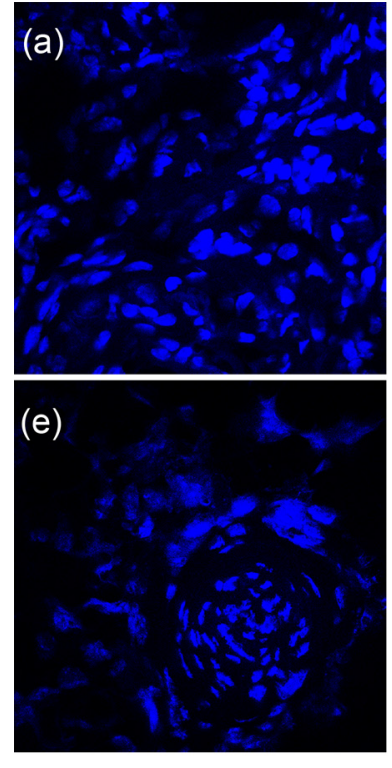

(i)
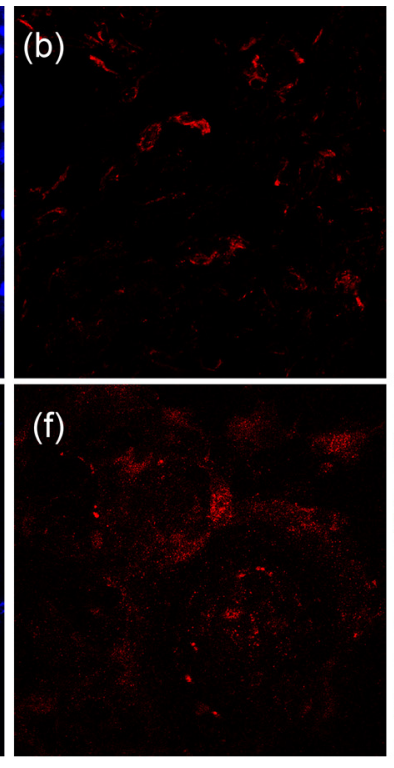

(f)

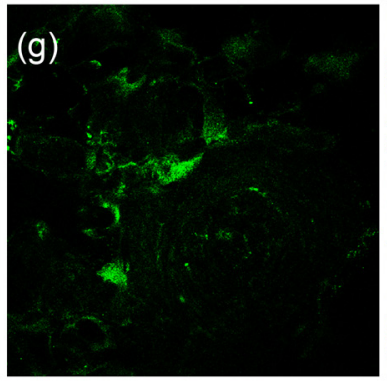

(j)

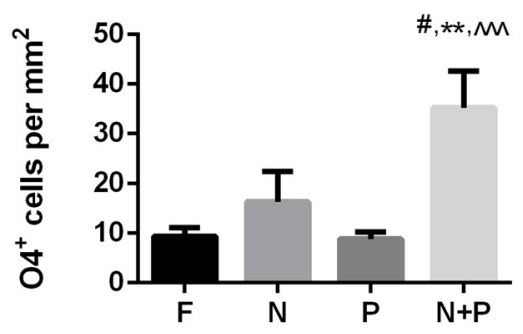

(k)

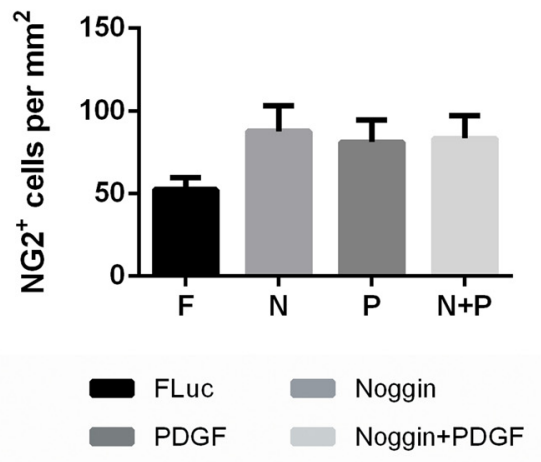

(I)
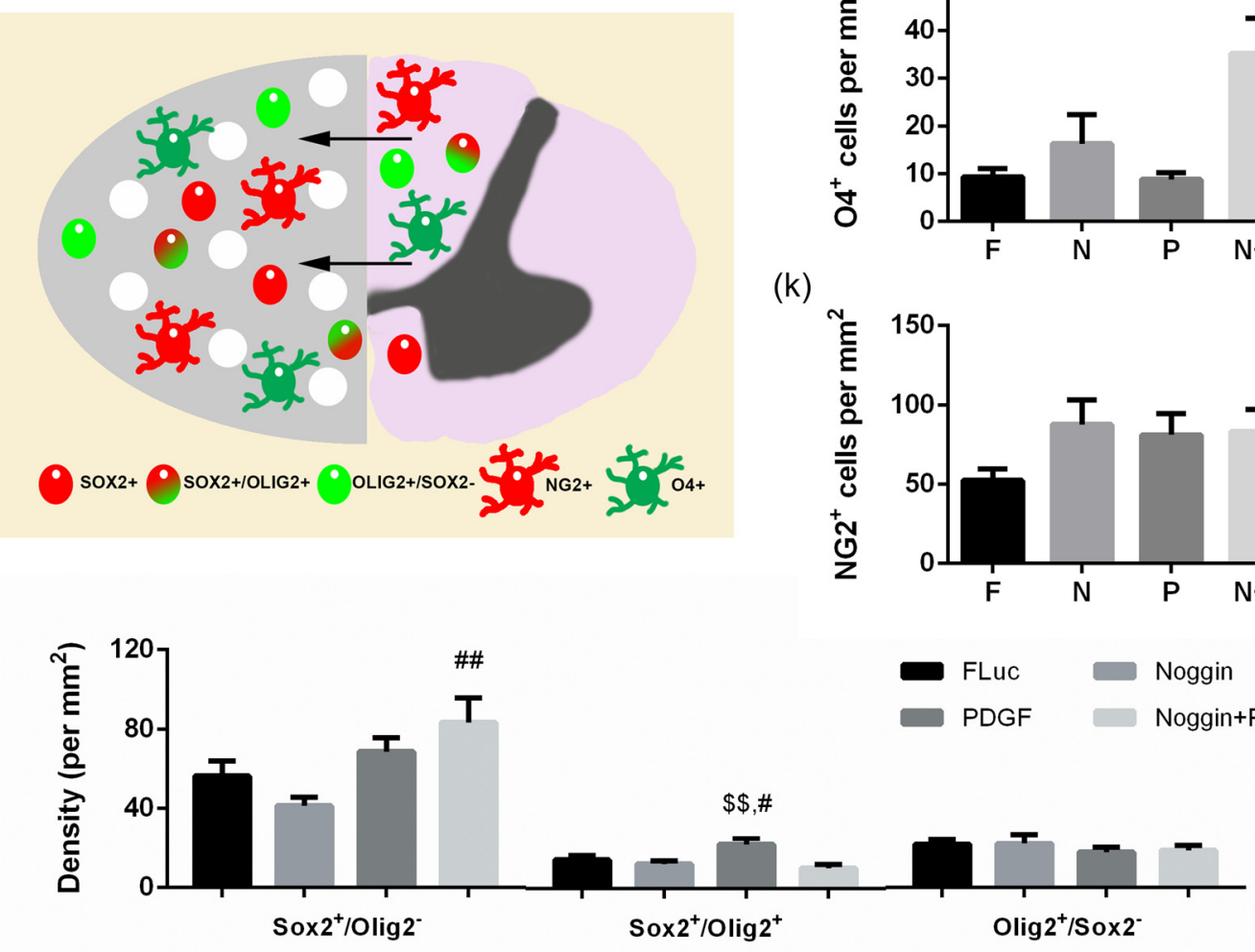

FIGURE 6 Oligodendrocyte-lineage cells in bridge implants at 8 weeks after injury. Images are representative of positive cell counts. (a-d) Oligodendrocyte-lineage cells at 8 weeks after injury. (a) Hoechst, (b) $\mathrm{NG}^{+}$, and (c) $\mathrm{O4}^{+}$expression in bridge implants. (d) Merged image. Yellow arrows denote $\mathrm{NG}^{+}$cells. White arrows denote $\mathrm{O}^{+}$cells. Scale: $20 \mu \mathrm{m}$. (e-h) Neural progenitor cells at 8 weeks after injury. (e) Hoechst, (f) Sox $2^{+}$, and (g) Olig2 $2^{+}$expression in bridge implants. (h) Merged image shows single expression and coexpression of Sox 2 and Olig2. White arrows indicate positive nuclei for coexpression. Brightness and contrast were adjusted for clarity. Scale: $20 \mu \mathrm{m}$. (i) Schematic of infiltration of cells into bridge implants from uninjured contralateral tissue following injury. Cells nearest the midline migrate into the bridge to support regenerating axons. (j) Quantification of $\mathrm{O}^{+}$cells. (k) Quantification of $\mathrm{NG2}^{+}$cells. (f) Quantification of neural progenitor cell phenotype densities. Data presented as mean \pm S.E.M. ${ }^{* *} p<0.01$ versus FLuc, ${ }^{\#} p<0.05$ versus Noggin, ${ }^{\# \#} p<0.01$ versus Noggin, ${ }^{\$ \$} p<0.01$ versus Noggin+ PDGF, $\wedge^{\wedge} \wedge p<0.001$ versus PDGF. $N=6$ per condition. PDGF: platelet-derived growth factor; S.E.M.: standard error of the mean [Color figure can be viewed at wileyonlinelibrary.com] 
Interestingly, the combined delivery of noggin+PDGF encoding lentivirus significantly increased the presence of $\mathrm{O}^{+}$preoligodendrocytes. The noggin+PDGF overexpression significantly increased Sox $2^{+} /$Olig $^{-}$cell density compared to noggin alone and had a similar density compared with PDGF. This result suggests the decrease in Sox $2^{+} /$Olig2 $^{-}$caused by noggin delivery may have been offset by PDGF codelivery. Codelivery also resulted in significantly lower densities of Olig2 ${ }^{+}$cells compared with those of other conditions. However, the density of $\mathrm{O}^{+}$preoligodendrocytes was increased fourfold relative to control and PDGF conditions and twofold relative to noggin alone. Noggin alone increased the density of immature oligodendrocytes, yet when paired with PDGF, the increase was further enhanced. Although these cells were $\mathrm{O}^{+}$, many cells did not exhibit a typical oligodendrocyte morphology. The $\mathrm{O} 4$ marker for differentiation is expressed at many stages of oligodendrocyte lineage so positive cells may not resemble the classical mature oligodendrocyte morphology. Furthermore, biomaterials and $\mathrm{SCl}$ have varying effects on the morphology of cells dependent on stiffness, modulus, and severity of injury (Aizawa, Leipzig, Zahir, \& Shoichet, 2008; Lourenço \& Grãos, 2016; Mclver et al., 2010; Russell \& Lampe, 2017), thus cells may not exhibit classical morphology due to biomaterial interactions and injury. However, we note that $\mathrm{O}^{+}$ cells are lineage locked to becoming myelinating oligodendrocytes (Nishiyama, Komitova, Suzuki, \& Zhu, 2009). These findings suggest that combinatorial delivery of inductive factors can considerably enhance the recruitment and differentiation of endogenous OPCs that persist at long timepoints.

Collectively, we report the ability of noggin+PDGF to promote remyelination by endogenous progenitor cells post-SCI. Codelivery of noggin+PDGF encoding lentivirus significantly increased total myelinated axon density and percentage. Codelivery also promoted greater myelination by oligodendrocytes compared with those of all other conditions ( $22 \%$ vs. $11 \%$ ). This result was consistent with the increased density of $\mathrm{O}^{+}$preoligodendrocytes via codelivery. Overall, we have demonstrated that lentivirus-based expression of multiple factors, such as noggin and PDGF, from multichannel PLG bridges, provides a strategy for identifying synergistic actions with the potential to target multiple barriers to regeneration.

Bridges are increasingly being considered for both penetrating wounds as well as for chronic injuries in which the scar is surgically resected that creates a defect (Xiao et al., 2016). While the bridge provides a path and support for axon regeneration, it is insufficient alone to promote regeneration. As we have shown, PDGF and noggin may be used to recruit and differentiate endogenous progenitors after $\mathrm{SCl}$ to encourage remyelination. Lentivirus represents an effective strategy to increase and sustain levels of these target proteins at the injury. Lentiviral vectors are currently in clinical trials (Milone \& O'Doherty, 2018) and, at a minimum, represent a tool to identify factors or combinations of factors that enhance myelination. An alternative to lentivirus delivery would be the direct delivery of these proteins, which is being attempted by various delivery strategies (Walthers \& Seidlits, 2015). This combination of a bridge to support and direct axon growth with a strategy to enhance their myelination represents a potential clinically translatable treatment for SCl.

\section{ORCID}

Lonnie D. Shea (D) http://orcid.org/0000-0002-9296-9673

\section{REFERENCES}

Abdellatif, A. A., Pelt, J. L., Benton, R. L., Howard, R. M., Tsoulfas, P., Ping, P., ... Whittemore, S. R. (2006). Gene delivery to the spinal cord: Comparison between lentiviral, adenoviral, and retroviral vector delivery systems. Journal of Neuroscience Research, 84(3), 553-567. https://doi.org/10.1002/jnr.20968

Aizawa, Y., Leipzig, N., Zahir, T., \& Shoichet, M. (2008). The effect of immobilized platelet-derived growth factor-AA on neural stem/ progenitor cell differentiation on cell-adhesive hydrogels. Biomaterials, 29(35), 4676-4683. https://doi.org/10.1016/j.biomaterials.2008. 08.018

Alizadeh, A., Dyck, S. M., Kataria, H., Shahriary, G. M., Nguyen, D. H., Santhosh, K. T., \& Karimi-Abdolrezaee, S. (2017). Neuregulin-1 positively modulates glial response and improves neurological recovery following traumatic spinal cord injury. Glia, 65(7), 11521175. https://doi.org/10.1002/glia.23150

Almad, A., Sahinkaya, F. R., \& McTigue, D. M. (2011). Oligodendrocyte fate after spinal cord injury. Neurotherapeutics, 8(2), 262-273. https://doi. org/10.1007/s13311-011-0033-5

Asakura, K., Hunter, S. F., \& Rodriguez, M. (1997). Effects of transforming growth factor-beta and platelet-derived growth factor on oligodendrocyte precursors: Insights gained from a neuronal cell line. Journal of Neurochemistry, 68(6), 2281-2290.

Barateiro, A., \& Fernandes, A. (2014). Temporal oligodendrocyte lineage progression: In vitro models of proliferation, differentiation and myelination. Biochimica et Biophysica Acta, 1843(9), 1917-1929. https://doi.org/10.1016/j.bbamcr.2014.04.018

Barnabé-Heider, F., Göritz, C., Sabelström, H., Takebayashi, H., Pfrieger, F. W., Meletis, K., \& Frisén, J. (2010). Origin of new glial cells in intact and injured adult spinal cord. Cell Stem Cell, 7(4), 470-482. https://doi. org/10.1016/j.stem.2010.07.014

Basso, D. M., Fisher, L. C., Anderson, A. J., Jakeman, L. B., McTigue, D. M., \& Popovich, P. G. (2006). Basso mouse scale for locomotion detects differences in recovery after spinal cord injury in five common mouse strains. Journal of Neurotrauma, 23(5), 635-659. https://doi.org/10. 1089/neu.2006.23.635

Beattie, M. S., Hermann, G. E., Rogers, R. C., \& Bresnahan, J. C. (2002). Cell death in models of spinal cord injury. Progress in Brain Research, 137, 37-47.

Boulanger, J. J., \& Messier, C. (2014). From precursors to myelinating oligodendrocytes: Contribution of intrinsic and extrinsic factors to white matter plasticity in the adult brain. Neuroscience, 269, 343-366. https://doi.org/10.1016/j.neuroscience.2014.03.063

Bradl, M., \& Lassmann, H. (2010). Oligodendrocytes: Biology and pathology. Acta Neuropathologica, 119(1), 37-53. https://doi.org/10. 1007/s00401-009-0601-5

Bunge, M. B. (2001). Bridging areas of injury in the spinal cord. Neuroscientist, 7(4), 325-339. https://doi.org/10.1177/107385840100700409

Butt, A. M., Hornby, M. F., Kirvell, S., \& Berry, M. (1997). Platelet-derived growth factor delays oligodendrocyte differentiation and axonal myelination in vivo in the anterior medullary velum of the developing rat. Journal of Neuroscience Research, 48(6), 588-596.

Cao, Q., He, Q., Wang, Y., Cheng, X., Howard, R. M., Zhang, Y., ... Whittemore, S. R. (2010). Transplantation of ciliary neurotrophic 
factor-expressing adult oligodendrocyte precursor cells promotes remyelination and functional recovery after spinal cord injury. Journal of Neuroscience, 30(8), 2989-3001. https://doi.org/10.1523/jneurosci. 3174-09.2010

Casha, S., Yu, W. R., \& Fehlings, M. G. (2001). Oligodendroglial apoptosis occurs along degenerating axons and is associated with FAS and p75 expression following spinal cord injury in the rat. Neuroscience, 103(1), 203-218.

Chen, B. K., Madigan, N. N., Hakim, J. S., Dadsetan, M., McMahon, S. S., Yaszemski, M. J., \& Windebank, A. J. (2017). GDNF Schwann cells in hydrogel scaffolds promote regional axon regeneration, remyelination and functional improvement after spinal cord transection in rats.. Journal of Tissue Engineering and Regenerative Medicine, 12(1), e398-e407.

Chen, Y., Balasubramaniyan, V., Peng, J., Hurlock, E. C., Tallquist, M., Li, J., \& Lu, Q. R. (2007). Isolation and culture of rat and mouse oligodendrocyte precursor cells. Nature Protocols, 2(5), 1044-1051.

Chung, K., \& Coggeshall, R. E. (1983a). Numbers of axons in lateral and ventral funiculi of rat sacral spinal cord. The Journal of Comparative Neurology, 214(1), 72-78. https://doi.org/10.1002/cne.902140107

Chung, K., \& Coggeshall, R. E. (1983b). Propriospinal fibers in the rat. The Journal of Comparative Neurology, 217(1), 47-53. https://doi.org/10. 1002/cne. 902170105

Delgado, A. C., Ferrón, S. R., Vicente, D., Porlan, E., Perez-Villalba, A., Trujillo, C. M., ... Fariñas, I. (2014). Endothelial NT-3 delivered by vasculature and CSF promotes quiescence of subependymal neural stem cells through nitric oxide induction. Neuron, 83(3), 572-585. https://doi.org/10.1016/j.neuron.2014.06.015

Deng, L. X., Deng, P., Ruan, Y., Xu, Z. C., Liu, N. K., Wen, X., ... Xu, X. M. (2013). A novel growth-promoting pathway formed by GDNF-overexpressing Schwann cells promotes propriospinal axonal regeneration, synapse formation, and partial recovery of function after spinal cord injury. Journal of Neuroscience, 33(13), 5655-5667. https://doi. org/10.1523/jneurosci.2973-12.2013

Donnelly, D. J., \& Popovich, P. G. (2008). Inflammation and its role in neuroprotection, axonal regeneration and functional recovery after spinal cord injury. Experimental Neurology, 209(2), 378-388. https:// doi.org/10.1016/j.expneurol.2007.06.009

Duncan, I. D., Brower, A., Kondo, Y., Curlee, J. F., \& Schultz, R. D. (2009). Extensive remyelination of the CNS leads to functional recovery. Proceedings of the National Academy of Sciences of the United States of America, 106(16), 6832-6836. https://doi.org/10.1073/pnas. 0812500106

Duncan, I. D., Marik, R. L., Broman, A. T., \& Heidari, M. (2017). Thin myelin sheaths as the hallmark of remyelination persist over time and preserve axon function. Proceedings of the National Academy of Sciences of the United States of America, 114(45), E9685-E9691. https://doi.org/ 10.1073/pnas.1714183114

Enzmann, G. U., Benton, R. L., Woock, J. P., Howard, R. M., Tsoulfas, P., \& Whittemore, S. R. (2005). Consequences of noggin expression by neural stem, glial, and neuronal precursor cells engrafted into the injured spinal cord. Experimental Neurology, 195(2), 293-304. https:// doi.org/10.1016/j.expneurol.2005.04.021

Fitch, M. T., \& Silver, J. (2008). CNS injury, glial scars, and inflammation: Inhibitory extracellular matrices and regeneration failure. Experimental Neurology, 209(2), 294-301. https://doi.org/S0014-4886(07) 00213-0. [pii] 10.1016/j.expneurol.2007.05.014

Fortun, J., Hill, C. E., \& Bunge, M. B. (2009). Combinatorial strategies with Schwann cell transplantation to improve repair of the injured spinal cord. Neuroscience Letters, 456(3), 124-132. https://doi.org/10.1016/j. neulet.2008.08.092

Gritli-Linde, A., Lewis, P., McMahon, A. P., \& Linde, A. (2001). The whereabouts of a morphogen: Direct evidence for short- and graded long-range activity of hedgehog signaling peptides. Developmental Biology, 236(2), 364-386. https://doi.org/10.1006/dbio.2001.0336
Hawryluk, G. W. J., \& Fehlings, M. G. (2008). The center of the spinal cord may be central to Its repair. Cell Stem Cell, 3(3), 230-232. https://doi. org/http://dx.org/10.1016/j.stem.2008.08.009

Hill, R. A., Patel, K. D., Medved, J., Reiss, A. M., \& Nishiyama, A. (2013). NG2 cells in white matter but not gray matter proliferate in response to PDGF. Journal of Neuroscience, 33(36), 14558-14566. https://doi. org/10.1523/JNEUROSCI.2001-12.2013

Hinks, G. L., \& Franklin, R. J. M. (1999). Distinctive patterns of PDGF-A, FGF-2, IGF-I, and TGF-beta1 gene expression during remyelination of experimentally-induced spinal cord demyelination. Molecular and Cellular Neuroscience, 14(2), 153-168. https://doi.org/10.1006/mcne. 1999.0771

Horky, L. L., Galimi, F., Gage, F. H., \& Horner, P. J. (2006). Fate of endogenous stem/progenitor cells following spinal cord injury. Journal of Comparative Neurology, 498(4), 525-538. https://doi.org/10.1002/ cne. 21065

Hsu, J. Y., Stein, S. A., \& Xu, X. M. (2006). Development of the corticospinal tract in the mouse spinal cord: A quantitative ultrastructural analysis. Brain Research, 1084(1), 16-27. https://doi.org/10.1016/j.brainres. 2006.02.036

Hu, J. G., Fu, S. L., Wang, Y. X., Li, Y., Jiang, X. Y., Wang, X. F., ... Xu, X. M. (2008). Platelet-derived growth factor-AA mediates oligodendrocyte lineage differentiation through activation of extracellular signalregulated kinase signaling pathway. Neuroscience, 151(1), 138-147. https://doi.org/10.1016/j.neuroscience.2007.10.050

Hughes, S. M., Moussavi-Harami, F., Sauter, S. L., \& Davidson, B. L. (2002). Viral-mediated gene transfer to mouse primary neural progenitor cells. Molecular Therapy, 5(1), 16-24. https://doi.org/10.1006/mthe. 2001.0512

Kadoya, K., Tsukada, S., Lu, P., Coppola, G., Geschwind, D., Filbin, M. T., ... Tuszynski, M. H. (2009). Combined intrinsic and extrinsic neuronal mechanisms facilitate bridging axonal regeneration one year after spinal cord injury. Neuron, 64(2), 165-172. https://doi.org/10.1016/j. neuron.2009.09.016

Karimi-Abdolrezaee, S., Eftekharpour, E., Wang, J., Morshead, C. M., \& Fehlings, M. G. (2006). Delayed transplantation of adult neural precursor cells promotes remyelination and functional neurological recovery after spinal cord injury. Journal of Neuroscience, 26(13), 3377-3389. https://doi.org/10.1523/jneurosci.4184-05.2006

Laporte, L. D., Yang, Y., Zelivyanskaya, M. L., Cummings, B. J., Anderson, A. J., \& Shea, L. D. (2009). Plasmid releasing multiple channel bridges for transgene expression after spinal cord injury. Molecular Therapy, 17(2), 318-326. https://doi.org/10.1038/mt.2008.252

Lasiene, J., Shupe, L., Perlmutter, S., \& Horner, P. (2008). No evidence for chronic demyelination in spared axons after spinal cord injury in a mouse. Journal of Neuroscience, 28(15), 3887-3896. https://doi.org/10. 1523/JNEUROSCI.4756-07.2008

Lee, H. J., Wu, J., Chung, J., \& Wrathall, J. R. (2013). SOX2 expression is upregulated in adult spinal cord after contusion injury in both oligodendrocyte lineage and ependymal cells. Journal of Neuroscience Research, 91(2), 196-210. https://doi.org/10.1002/jnr.23151

Li, G. L., Farooque, M., Holtz, A., \& Olsson, Y. (1999). Apoptosis of oligodendrocytes occurs for long distances away from the primary injury after compression trauma to rat spinal cord. Acta Neuropathologica, 98(5), 473-480.

Li, J., \& Lepski, G. (2013). Cell transplantation for spinal cord injury: A systematic review. BioMed Research International, 2013, 786475-32. https://doi.org/10.1155/2013/786475

Li, J., Rickett, T. A., \& Shi, R. (2009). Biomimetic nerve scaffolds with aligned intraluminal microchannels: A "sweet" approach to tissue engineering. Langmuir, 25(3), 1813-1817. https://doi.org/10.1021/ la803522f

Liu, A., \& Niswander, L. A. (2005). Bone morphogenetic protein signalling and vertebrate nervous system development. Nature Reviews Neuroscience, 6(12), 945-954. https://doi.org/10.1038/nrn1805 
Lourenço, T., \& Grãos, M. (2016). Modulation of oligodendrocyte differentiation by mechanotransduction. Frontiers in Cellular Neuroscience, 10(277) https://doi.org/10.3389/fncel.2016.00277

Lowry, N., Goderie, S. K., Lederman, P., Charniga, C., Gooch, M. R., Gracey, K. D., ... Temple, S. (2012). The effect of long-term release of Shh from implanted biodegradable microspheres on recovery from spinal cord injury in mice. Biomaterials, 33(10), 2892-2901. https://doi.org/10. 1016/j.biomaterials.2011.12.048

Lutton, C., Young, Y. W., Williams, R., Meedeniya, A. C., Mackay-Sim, A., \& Goss, B. (2012). Combined VEGF and PDGF treatment reduces secondary degeneration after spinal cord injury. Journal of Neurotrauma, 29(5), 957-970. https://doi.org/10.1089/neu.2010.1423

Lytle, J. M., \& Wrathall, J. R. (2007). Glial cell loss, proliferation, and replacement in the contused murine spinal cord. European Journal of Neuroscience, 25(6), 1711-1724. https://doi.org/10.1111/j.14609568.2007.05390.x

Margul, D. J., Park, J., Boehler, R. M., Smith, D. R., Johnson, M. A., McCreedy, D. A., ... Seidlits, S. K. (2016). Reducing neuroinflammation by delivery of IL-10 encoding lentivirus from multiple-channel bridges. Bioengineering \& Translational Medicine, 1, 136-148. https://doi.org/10. 1002/btm2.10018

Marti, E., \& Bovolenta, P. (2002). Sonic hedgehog in CNS development: One signal, multiple outputs. Trends in Neurosciences, 25(2), 89-96.

McCreedy, D. A., Margul, D. J., Seidlits, S. K., Antane, J. T., Thomas, R. J., Sissman, G. M., ... Shea, L. D. (2016). Semi-automated counting of axon regeneration in poly (lactide co-glycolide) spinal cord bridges. Journal of Neuroscience Methods, 263, 15-22. https://doi.org/10.1016/j. jneumeth.2016.01.021

Mclver, S. R., Muccigrosso, M., Gonzales, E. R., Lee, J. M., Roberts, M. S., Sands, M. S., \& Goldberg, M. P. (2010). Oligodendrocyte degeneration and recovery after focal cerebral ischemia. Neuroscience, 169(3), 1364-1375. https://doi.org/10.1016/j.neuroscience.2010.04.070

Mi, S., Miller, R. H., Tang, W., Lee, X., Hu, B., Wu, W., ... Pepinsky, B. (2009). Promotion of central nervous system remyelination by induced differentiation of oligodendrocyte precursor cells. Annals of Neurology, 65(3), 304-315. https://doi.org/10.1002/ana.21581

Milone, M. C., \& O'Doherty, U. (2018). Clinical use of lentiviral vectors. Leukemia, 32(7), 1529-1541. https://doi.org/10.1038/s41375-0180106-0

Miron, V. E., Kuhlmann, T., \& Antel, J. P. (2011). Cells of the oligodendroglial lineage, myelination, and remyelination. Biochimica et Biophysica Acta, 1812 (2), 184-193. https://doi.org/10.1016/j.bbadis.2010.09.010

Nishiyama, A., Komitova, M., Suzuki, R., \& Zhu, X. (2009). Polydendrocytes (NG2 cells): Multifunctional cells with lineage plasticity. Nature Reviews Neuroscience, 10(1), 9-22. https://doi.org/10.1038/nrn2495

Pawar, K., Cummings, B. J., Thomas, A., Shea, L. D., Levine, A., Pfaff, S., \& Anderson, A. J. (2015). Biomaterial bridges enable regeneration and reentry of corticospinal tract axons into the caudal spinal cord after SCl: Association with recovery of forelimb function. Biomaterials, 65, 1-12. https://doi.org/10.1016/j.biomaterials.2015.05.032

Pearse, D. D., \& Barakat, D. J. (2006). Cellular repair strategies for spinal cord injury. Expert Opinion on Biological Therapy, 6(7), 639-652. https://doi.org/10.1517/14712598.6.7.639

Powers, B. E., Lasiene, J., Plemel, J. R., Shupe, L., Perlmutter, S. I., Tetzlaff, W., \& Horner, P. J. (2012). Axonal thinning and extensive remyelination without chronic demyelination in spinal injured rats. The Journal of Neuroscience, 32(15), 5120-5125. https://doi.org/10.1523/ JNEUROSCI.0002-12.2012

Powers, B. E., Sellers, D. L., Lovelett, E. A., Cheung, W., Aalami, S. P., Zapertov, N., ... Horner, P. J. (2013). Remyelination reporter reveals prolonged refinement of spontaneously regenerated myelin. Proceedings of the National Academy of Sciences of the United States of America, 110(10), 4075-4080. https://doi.org/10.1073/pnas.1210293110

Ribes, V., \& Briscoe, J. (2009). Establishing and interpreting graded sonic hedgehog signaling during vertebrate neural tube patterning: The role of negative feedback. Cold Spring Harbor Perspectives in Biology, 1(2), a002014. https://doi.org/10.1101/cshperspect.a002014

Richardson, P. M., McGuinness, U. M., \& Aguayo, A. J. (1980). Axons from CNS neurons regenerate into PNS grafts. Nature, 284(5753), 264-265.

Russell, L. N., \& Lampe, K. J. (2017). Oligodendrocyte precursor cell viability, proliferation, and morphology is dependent on mesh size and storage modulus in 3D poly(ethylene glycol)-based hydrogels. ACS Biomaterials Science \& Engineering, 3(12), 3459-3468. https://doi.org/ 10.1021/acsbiomaterials.7b00374

Sabelström, H., Stenudd, M., \& Frisén, J. (2014). Neural stem cells in the adult spinal cord. Experimental Neurology, 260, 44-49. https://doi.org/ 10.1016/j.expneurol.2013.01.026

Sabo, J. K., Aumann, T. D., Merlo, D., Kilpatrick, T. J., \& Cate, H. S. (2011). Remyelination is altered by bone morphogenic protein signaling in demyelinated lesions. Journal of Neuroscience, 31(12), 4504-4510. https://doi.org/10.1523/jneurosci.5859-10.2011

Schmidt, C. E., \& Leach, J. B. (2003). Neural tissue engineering: Strategies for repair and regeneration. Annual Review of Biomedical Engineering, 5, 293-347. https://doi.org/10.1146/annurev.bioeng.5.011303.120731

Schwab, M. E. (2002). Repairing the injured spinal cord. Science, 295 (5557), 1029-1031. https://doi.org/10.1126/science.1067840

Sellers, D. L., Maris, D. O., \& Horner, P. J. (2009). Postinjury niches induce temporal shifts in progenitor fates to direct lesion repair after spinal cord injury. Journal of Neuroscience, 29(20), 6722-6733. https://doi. org/10.1523/jneurosci.4538-08.2009

Tan, B. T., Jiang, L., Liu, L., Yin, Y., Luo, Z. R. X., Long, Z. Y., ... Liu, Y. (2017). Local injection of Lenti-Olig2 at lesion site promotes functional recovery of spinal cord injury in rats. CNS Neuroscience \& Therapeutics, 23(6), 475-487. https://doi.org/10.1111/cns.12694

Tetzlaff, W., Okon, E. B., Karimi-Abdolrezaee, S., Hill, C. E., Sparling, J. S., Plemel, J. R., ... Kwon, B. K. (2011). A systematic review of cellular transplantation therapies for spinal cord injury. Journal of Neurotrauma, 28(8), 1611-1682. https://doi.org/10.1089/neu.2009.1177

Thomas, A. M., Kubilius, M. B., Holland, S. J., Seidlits, S. K., Boehler, R. M., Anderson, A. J., ... Shea, L. D. (2013). Channel density and porosity of degradable bridging scaffolds on axon growth after spinal injury. Biomaterials, 34(9), 2213-2220. https://doi.org/10.1016/j.biomaterials. 2012.12.002

Thomas, A. M., Seidlits, S. K., Goodman, A. G., Kukushliev, T. V., Hassani, D. M., Cummings, B. J., ... Shea, L. D. (2014). Sonic hedgehog and neurotrophin-3 increase oligodendrocyte numbers and myelination after spinal cord injury. Integrative Biology, 6(7), 694-705. https://doi. org/10.1039/c4ib00009a

Thomas, A. M., \& Shea, L. D. (2013). Polysaccharide-modified scaffolds for controlled lentivirus delivery in vitro and after spinal cord injury. Journal of Controlled Release, 170(3), 421-429. https://doi.org/10. 1016/j.jconrel.2013.06.013

Tuinstra, H. M., Aviles, M. O., Shin, S., Holland, S. J., Zelivyanskaya, M. L., Fast, A. G., ... Shea, L. D. (2012). Multifunctional, multichannel bridges that deliver neurotrophin encoding lentivirus for regeneration following spinal cord injury. Biomaterials, 33(5), 1618-1626. https:// doi.org/10.1016/j.biomaterials.2011.11.002

Tuinstra, H. M., Margul, D. J., Goodman, A. G., Boehler, R. M., Holland, S. J., Zelivyanskaya, M. L., ... Shea, L. D. (2014). Long-term characterization of axon regeneration and matrix changes using multiple channel bridges for spinal cord regeneration. Tissue Engineering. Part A, 20(5-6), 1027-1037. https://doi.org/10.1089/ten.tea.2013.0111

Walthers, C. M., \& Seidlits, S. K. (2015). Gene delivery strategies to promote spinal cord repair. Biomarker insights, 10(Suppl 1), 11-29. https://doi.org/10.4137/BMI.S20063

Wang, Z., Colognato, H., \& Ffrench-Constant, C. (2007). Contrasting effects of mitogenic growth factors on myelination in neuronoligodendrocyte cocultures. Glia, 55(5), 537-545. https://doi.org/10. 1002/glia.20480 
Wang, M., Zhai, P., Chen, X., Schreyer, D. J., Sun, X., \& Cui, F. (2011). Bioengineered scaffolds for spinal cord repair. Tissue Engineering Part B: Reviews, 17(3), 177-194. https://doi.org/10.1089/ten.teb. 2010.0648

Woodruff, R. H., Fruttiger, M., Richardson, W. D., \& Franklin, R. J. M. (2004). Platelet-derived growth factor regulates oligodendrocyte progenitor numbers in adult CNS and their response following CNS demyelination. Molecular and Cellular Neuroscience, 25(2), 252-262. https://doi.org/10.1016/j.mcn.2003.10.014

Xiao, Q., Du, Y., Wu, W., \& Yip, H. K. (2010). Bone morphogenetic proteins mediate cellular response and, together with Noggin, regulate astrocyte differentiation after spinal cord injury. Experimental Neurology, 221(2), 353-366. https://doi.org/10.1016/j.expneurol.2009.12.003

Xiao, Z., Tang, F., Tang, J., Yang, H., Zhao, Y., Chen, B., ... Dai, J. (2016). One-year clinical study of NeuroRegen scaffold implantation following scar resection in complete chronic spinal cord injury patients. Science China Life Sciences, 59(7), 647-655. https://doi.org/10.1007/ s11427-016-5080-z

Yang, Y., Laporte, L. D., Zelivyanskaya, M. L., Whittlesey, K. J., Anderson, A. J., Cummings, B. J., \& Shea, L. D. (2009). Multiple channel bridges for spinal cord injury: Cellular characterization of host response. Tissue Engineering. Part A, 15(11), 3283-3295. https://doi.org/10. 1089/ten.TEA.2009.0081
Zhang, S., Huang, F., Gates, M., \& Holmberg, E. G. (2013). Role of endogenous Schwann cells in tissue repair after spinal cord injury. Neural Regeneration Research, 8(2), 177-185. https://doi.org/10.3969/ j.issn.1673-5374.2013.02.011

Zhang, H., Vutskits, L., Calaora, V., Durbec, P., \& Kiss, J. Z. (2004). A role for the polysialic acid-neural cell adhesion molecule in PDGF-induced chemotaxis of oligodendrocyte precursor cells. Journal of Cell Science, 117(Pt 1), 93-103. https://doi.org/10.1242/jcs.00827

Zhou, X., Vink, M., Klaver, B., Berkhout, B., \& Das, A. T. (2006). Optimization of the Tet-On system for regulated gene expression through viral evolution. Gene Therapy, 13(19), 1382-1390. https://doi. org/10.1038/sj.gt.3302780

How to cite this article: Smith DR, Margul DJ, Dumont CM, et al. Combinatorial lentiviral gene delivery of prooligodendrogenic factors for improving myelination of regenerating axons after spinal cord injury. Biotechnology and Bioengineering. 2019;116:155-167.

https://doi.org/10.1002/bit.26838 